\title{
Outcomes of religious and spiritual adaptations to psychotherapy: A meta-analytic review
}

Timothy B. Smith

Brigham Young University, tbs@byu.edu

Jeremy Bartz

Brigham Young University

P. Scott Richards

Brigham Young University, scott_richards@byu.edu

Follow this and additional works at: https://scholarsarchive.byu.edu/facpub

Part of the Counseling Psychology Commons, and the Religion Commons

\section{Original Publication Citation}

Smith, T. B., Bartz, J. D., \& Richards, P. S. (2007). Outcomes of religious and spiritual adaptations to psychotherapy: A meta-analytic review. Psychotherapy Research, 17, 643-655.

\section{BYU ScholarsArchive Citation}

Smith, Timothy B.; Bartz, Jeremy; and Richards, P. Scott, "Outcomes of religious and spiritual adaptations to psychotherapy: A meta-analytic review" (2007). Faculty Publications. 2026.

https://scholarsarchive.byu.edu/facpub/2026

This Peer-Reviewed Article is brought to you for free and open access by BYU ScholarsArchive. It has been accepted for inclusion in Faculty Publications by an authorized administrator of BYU ScholarsArchive. For more information, please contact ellen_amatangelo@byu.edu. 
Smith, T. B., Bartz, J. D., \& Richards, P. S. (2007). Outcomes of religious and spiritual adaptations to psychotherapy: A meta-analytic review. Psychotherapy Research, 17, 643-655.

Outcomes of Religious and Spiritual Adaptations to Psychotherapy:

A Meta-Analytic Review

Timothy B. Smith, Jeremy D. Bartz and P. Scott Richards

Brigham Young University

Department of Counseling Psychology

January 14, 2007

Correspondence concerning this manuscript should be directed to P. Scott Richards, Department of Counseling Psychology and Special Education, Brigham Young University, 340 MCKB, Provo, UT 84602. Work for this manuscript was supported through grants from Brigham Young University and TP Industrial, Inc.

Psychotherapy Research 


\begin{abstract}
The use of spiritually-oriented psychotherapies has increased dramatically during the past decade. This article reports a meta-analysis of 31 outcome studies of spiritual therapies that were conducted from 1984 - 2005 with clients suffering from a variety of psychological problems. Across the 31 studies the random effects weighted average effect size was $d=.56$. This finding provides some empirical evidence that spirituallyoriented psychotherapy approaches may be beneficial to individuals with certain psychological problems (e.g., depression, anxiety, stress, eating disorders, etc.). Recommendations for future research in this domain are offered.
\end{abstract}


Outcomes of Religious and Spiritual Adaptations to Psychotherapy:

\section{A Meta-Analytic Review}

The rise of a more spiritually-open zeitgeist or spirit of the times in the behavioral sciences has been favorable to the development of spiritually and religiously accommodative psychotherapies (McCullough, 1999; Miller, 1999; Richards \& Bergin, 2000, 2005; Sperry \& Shafranske, 2005). Spiritual interventions are being used with increasing frequency across all types of treatment, including, individual therapy (Richards \& Bergin, 2003), group therapy (Hiatt, 1999), marriage and family therapy (Butler \& Harper, 1994), and child and adolescent therapy (Miller, 2004). Spiritual perspectives and interventions have now been incorporated into most mainstream theoretical orientations, including, the psychoanalytic tradition (Shafranske, 2004), Adlerian therapy (Watts, 2000), behavior therapy (Martin \& Booth, 1999), cognitive therapy (Propst, 1996), rational-emotive behavior therapy (Nielson, Johnson \& Ellis, 2001), person-centered therapy (West, 2004), existential-humanistic therapy (Mahrer, 1996), Gestalt therapy (Harris, 2000), constructivism (Steinfeld, 2000) and transactional analysis (Trautmann, 2003). Religion and spirituality are also increasingly seen as important aspects of client diversity, with spiritual perspectives and interventions being incorporated into treatment with various multicultural and special client populations (e.g. Richards \& Bergin, 2000; Smith \& Richards, 2005). Clearly, the integration of spiritual and religious issues into psychotherapy has received extensive attention in the recent research literature.

The term spirituality refers to transcendent experiences with and understandings about God and/or other forces in the universe, whereas the term religious refers to an 
institutionalized system of beliefs, values, and activities based upon spiritual creeds (Kelly, 1995). Individuals can be both spiritual and religious, primarily religious but not particularly spiritual, or primarily spiritual but not religious. Both concepts have consistently been found to be relevant to mental health (Koenig, 1998), and religious/spiritual approaches to psychotherapy have the potential to address clients' religious/spiritual concerns when relevant and to involve language and interventions that demonstrate respect for clients' religious/spiritual contexts. In addition, religious/spiritual treatment approaches have the potential of being more congruent with client values and of working with the methods of religious and spiritual coping already present in clients' religious and spiritual worldviews. For the sake of simplicity, we will primarily use the broader term spiritual throughout this manuscript.

Spiritual treatment approaches involve a wide variety of specific spiritual techniques or interventions. Several survey studies have documented these spiritual interventions and the relative frequency with which they are used (Ball \& Goodyear, 1991; Raphel, 2001; Richards \& Potts, 1995; Shafranske, 2000, 2001). The interventions most frequently used in psychotherapy tend to be private prayer for clients, teaching religious and spiritual concepts, encouraging forgiveness, evaluating clients' religious/spiritual history, and making reference to scriptures. Less frequently used interventions include spiritual meditation, religious relaxation and imagery, in-depth religious/spiritual assessments, and vocal in-session prayer.

The inclusion of religious/spiritual issues in psychotherapy creates the potential for several ethical dilemmas to arise (Richards \& Bergin, 2005). For example, appropriate informed consent must received (Hawkins \& Bullock, 1995); client spiritual 
identity development must be considered (Fowler, 1991; Hood et al., 1996); dual relationships must be monitored (Sonne, 1999); collaboration with religious leaders must be done sensitively (Chappelle, 2000); clients’ values must be respected (Haug, 1998); work setting boundaries must be maintained (Chappelle, 2000; Richards \& Bergin, 2005); and therapists must be competent to engage in such psycho-spiritual integration (Barnett \& Fiorentino, 2000; Lannert, 1991). Through such recommendations, practitioners have repeatedly been cautioned to avoid potential ethical pitfalls and to ensure that religion and spirituality are integrated into psychotherapy in ways that are beneficial for the client and congruent with professional ethics.

In spite of the notable increase of professional attention to the integration of religion and spirituality into clinical practice, there is still a deficit in the outcome research on the effectiveness of such integration with various clinical issues and populations. In a comprehensive Psychological Bulletin review, Worthington, Kurusu, McCollough, and Sanders’s (1996) examined 148 empirical studies on religion and psychotherapy, which provided considerable insight into religion and mental health. However, their review only included 8 outcome studies. They concluded that the methodological quality of this research has improved to the point of approaching "current secular standards, except in outcome research” (Worthington et al., 1996, p. 448). A subsequent meta-analysis examined five outcome studies of spiritually accommodative therapy (McCullough, 1999), and a later narrative review identified nine studies of primarily religiously accommodative cognitive therapy (Worthington \& Sandage, 2001). In general, these reviewers have concluded that (1) spiritually oriented treatment approaches are as effective, and sometimes more effective for religious clients compared 
to secular approaches; (2) most research has been done on potential, not actual, clients;

(3) generally, religiously devout clients prefer and trust counselors with similar religious beliefs and values; and (4) in general, research provides support for the therapeutic use of prayer, forgiveness, and meditation. However, given the sparse data available, all of these reviewers called for additional outcome research to be conducted.

Since the publication of the reviews mentioned above, dozens of additional outcome studies of spiritual treatment approaches have appeared in the literature. To gain a more in-depth understanding of the outcomes of spiritual treatment studies and their methodological strengths and limitations, we conducted an updated review of the literature. In order to overcome the difficulties and biases associated with narrative reviews we conducted a quantitative literature review (meta-analysis) that allowed for the systematic aggregation of data across studies and the statistical investigation of potential moderation effects. We located 31 studies that were suitable for meta-analysis and analyzed them statistically and critiqued them methodologically.

Method

\section{Literature Search Procedures}

In order to locate outcome studies regarding the impact of spiritual interventions on psychological variables we searched the following databases: PsycINFO, Social Science Abstracts, ERIC, and ALTA. To locate manuscripts involving the intended construct we used the root terms spirit, relig, faith, church, mosque, synagogue, temple, worship, or pray in either the title or abstract. We then crossed this search with the construct of psychotherapy using the root terms counsel, therap, psychotherapy, session, intake, intervene, or retention in the title or abstract. We then crossed the search with the 
construct of outcome using the root terms outcome, effective, efficacy, or compar in the title or abstract. The search was limited to the years 1981 to 2005. To obtain additional manuscripts we also reviewed the reference lists of previously published reviews of spiritually-oriented therapies (Johnson, 1993; McCullough, 1999; Worthington et al., 1996; Worthington \& Sandage, 2001).

Our inclusion criteria for the meta-analysis were that manuscripts had to be written in English and contain quantitative outcome data regarding a mental health intervention that had a spiritual or religious component or adaptation. Educational interventions, qualitative studies, and case studies were excluded. Applying these criteria to the retrieved articles, we identified 31 studies that were subsequently coded for analyses.

\section{Data Coding}

To decrease the likelihood of human error in coding data, a team of two raters coded each research manuscript that met the inclusion criteria. Team members helped one another to verify the accuracy of coding and data entry. Subsequently each article was coded by a different two-rater team. Inter-rater agreement was high for categorical variables (Cohen’s kappa averaged .87) and for continuous variables (intraclass correlations using one-way random effects models for single measures [Shrout \& Fleiss, 1979] averaged .85). Discrepancies across coding teams were resolved through scrutiny of the manuscripts by the first author of the study.

To enable meta-analytic analyses, the effect sizes extracted from each study were transformed to the metric of the standardized mean difference ( $d$; Cohen, 1987). Data reported in other formats (e.g., Chi-square, correlation, etc.) were transformed to $d$ 
coefficients using the Meta-analysis Calculator software (Lyons, 1996). When no statistic was provided but an analysis was reported as significant, we determined the standardized mean difference corresponding to the reported alpha level (assuming two-tailed alpha= .05 unless reported otherwise). When an analysis was reported as non-significant but no additional information was available, we set the effect size coefficient to $d=.00$. These procedures yielded conservative effect size estimates. In order to not to violate the statistical assumption of independent samples, we averaged all effect sizes within each study (weighted by the number of participants) such that each study only contributed a single effect size in the omnibus analyses. The direction of effect sizes was coded uniformly, such that positive values indicated greater client improvement as a function of the intervention provided.

Analyses

To aggregate effect sizes and to estimate the reliability of these aggregates, random effects models were calculated using SPSS macros developed by Lipsey and Wilson (2001). Rather than use a fixed effects approach, which assumes that every study evaluates the same effect, we analyzed the data using random effects models to account for between-studies variation (Mosteller \& Colditz, 1996). This procedure is more appropriate when attempting to generalize the results beyond the studies included in the analyses (Hedges \& Vevea, 1998).

Following the computation of the overall magnitude of the effect of spiritually adapted psychotherapy, random effects weighted regression models and analyses of variance (ANOVAs) were conducted to examine the influence of potential moderating variables. Such analyses are useful in determining circumstances under which the 
strength of the results may vary. Because the small number of studies located in the meta-analysis greatly restricted the associated level of statistical power, the level of statistical significance was set at $p<.10$ for the moderator analyses.

Results

\section{Descriptive Characteristics}

Statistically non-redundant effect sizes were extracted from 31 studies, with a total of 1,845 clients across all studies (see Table 1). Client gender was reported in 25 (81\%) of the studies, with an average of $73 \%$ of clients in studies being female. Across the 26 studies reporting client age, the average was 37.4 years. Religious affiliation was reported across 21 studies, with an average of 35\% Christians of unspecified denominations, 24\% Muslims, 17\% Protestants, 12\% Catholics, 9\% Latter-day Saints, 1\% Jews, and 2\% others (e.g., Buddhists, Hindus).

Descriptions of the spiritual interventions provided within studies revealed that 22 (71\%) were evaluations of group therapy, with 8 studies (26\%) involving individual therapy and 1 study not specifying the treatment modality. The average number of sessions provided was 10.3 , with a range of 1 to 26 sessions. Spiritual components that were common across studies included teaching spiritual/religious principles (45\%), client prayer (42\%), reading sacred texts (32\%), and religious imagery or spiritual meditation (32\%). The majority (52\%) of the interventions provided were based on cognitive or cognitive/behavioral therapy, with $13 \%$ based on humanistic therapy, 22\% based on nonpsychological religious teachings, and 13\% based on a combination of these approaches.

With regard to research design, 18 studies (59\%) involved true experimental designs with clients randomly assigned to a treatment condition or a control group, with 6 
(19\%) being quasi-experimental designs and 7 (22\%) being single group pre- to post-test designs. The vast majority of studies (29 studies, 92\%) using experimental and quasiexperimental designs involved at least one control group with an equivalent therapeutic intervention (i.e., cognitive therapy without spiritual components), but in two studies the control groups were non-equivalent conditions (i.e., waiting list). About half (16 studies, $52 \%)$ of the interventions were manualized to promote consistency across cases, and about one-third (9 studies, 29\%) involved fidelity checks to ensure implementation of the intended intervention components.

Omnibus Analysis

Across the 31 studies the random effects weighted average effect size was $d=.56$ $(S E=.07, p<.001,95 \%$ Confidence interval $=.43$ to .70$)$. Effect sizes ranged from -.55 to 1.63 , with the heterogeneity across studies being statistically significant $\left(Q_{(30)}=58.2\right.$, $p=.002$ ), suggesting that systematic effect size variability was unaccounted for. We therefore conducted additional analyses to determine the extent to which the variability in the effect sizes was moderated by other variables.

\section{Publication Bias}

As a first step, we conducted analyses to evaluate the possibility that the results were moderated by the publication status of the research manuscript. These analyses were essential because of (1) the likelihood for meta-analyses to include greater numbers of published than unpublished studies and (2) the likelihood for published studies to have effect sizes of greater magnitude than those of unpublished studies. Together these two trends can result in publication bias in the results of a meta-analysis. 
In our study, the 6 unpublished studies had an average effect size of $d=.49$ that was not significantly ( $p=.61$ ) less than that of the 25 published studies, $d=.58$. To assess for the possibility of publication bias, we first plotted a “funnel graph” (Begg, 1994) of the effect sizes by the total sample size of the study. Because studies with smaller sample sizes typically show greater variability in effect size than larger studies, and because there are fewer large studies than small studies, the resulting graph should resemble an inverse funnel. The data obtained from this meta-analysis generally conformed to the expected inverse funnel shape, with the notable exception of a sparse lower left hand corner, where studies of small sample size and negative effect sizes would be located (Figure 1). This result indicated that there were apparently several “missing” studies that likely remained unpublished because they obtained unfavorable findings. Hence, we needed to carefully consider how this apparently missing data may have impacted our findings.

As a next step, we calculated a fail-safe N (Rosenthal, 1979), which is the theoretical number of unpublished studies with effect sizes averaging zero (no effect) that would need to be located in order to reduce the overall magnitude of the results obtained to zero. Based on this calculation, at least 933 additional studies would need to be found to render negligible the omnibus results. It seems improbable that at least such a large number of additional studies on the topic have ever been conducted.

As a final step, we employed the "trim and fill” methodology described by Duval and Tweedie (2000a, 2000b) to estimate the number of studies missing due to publication bias and to recalculate the weighted mean effect sizes accordingly. Using this method, outlying studies that have no corresponding values on the opposite side of the distribution 
are temporarily removed (“trimmed”), and the mean effect size is recalculated, repeating the procedure until the distribution is symmetrical with respect to the mean. In our analyses, we followed the recommendations of Duval and Tweedie (2000b) in using $L_{0}{ }^{+}$ to estimate the number of "missing" studies. The final step in the procedure is to replace the "trimmed" studies along with "filled" estimated values of the "missing” studies on the other side of the funnel plot distribution. The values for the "filled" studies are the opposite of those "trimmed." The resulting data set including "filled” missing studies is then used to calculate a new omnibus effect size and its confidence intervals, with statistically non-significant values indicating potential publication bias. In the current study, the recalculated random effects weighted mean effect size was $d=.49(Q=75.0, p$ $<$.0001). Based on these analyses, publication bias seems an unlikely threat the overall results.

\section{Moderation by Client and Study Characteristics}

As mentioned earlier, it was important to ascertain whether the effectiveness of spiritual mental health interventions was moderated by other variables. Particularly, we evaluated differences across (1) client composition by gender and age, (2) research methodology (design and outcome measurement), and (3) characteristics of the intervention itself (modality, length of treatment, type of spiritual adaptation made, etc.).

To determine whether differences in the gender composition of the clients account for significant between-studies variance, we correlated the percentage of females from the 25 studies that reported client gender with the corresponding average effect size. Across these studies the random effects weighted correlation was .01 ( $p=.95)$. A similar analysis was conducted with the average clients' age reported within 26 studies, and the 
resulting random effects weighted correlation was -.17 $(p=.31)$. Therefore, the average gender and age composition of the research samples did not moderate the results obtained.

Clients were drawn from different settings across the 31 studies, so it was important to verify if the omnibus results reported earlier were moderated by these differences. We therefore conducted a random effects weighted ANOVA across five different types of settings. As seen in Table 2, the results did not reach statistical significance. Studies conducted in medical hospitals and clinics tended to have effect sizes of lower magnitude than studies conducted in mental health settings, but this result warrants future investigation given the small number of studies included in the analysis.

Because the 31 studies used different research designs and outcome measures, it was also important to ascertain if the overall results differed across these variables. As seen in Table 2 , studies involving experimental designs had an average effect size $(d=$ .51) that was similar in magnitude to the omnibus effect size reported earlier $(d=.56)$. As expected, experimental studies had an average effect size that was lower than that found in studies that involved evaluations of changes in a single group over time, although this difference did not reach statistical significance. Nevertheless, because these types of research designs evaluate substantially different outcomes, we re-calculated the omnibus effect size using only those 22 studies that explicitly compared the inclusion of spiritual interventions to other forms of treatment (e.g., religiously-oriented cognitive therapy vs. secular cognitive therapy), with 2 experimental studies involving no comparisons with a bona fide treatment (e.g., wait list controls) also being excluded from 
the analysis. The resulting value of $d=.51$ (SE $=.09, p<.001,95 \%$ Confidence interval $=.34$ to .68) did not substantively differ from the omnibus effect size reported previously. An analysis across the type of outcome measure used within studies did reach statistical significance (Table 2). Specifically, studies involving measures of positive functioning and well-being had average effect sizes that were approximately twice as large as those involving other types of assessments, although it should be noted that there were only four studies exclusively involving measures of positive functioning or wellbeing.

Studies located in this meta-analysis reported a variety of interventions, and differences across those interventions were also important to investigate. First of all, we contrasted studies providing individual therapy with those providing group therapy (Table 2). The differences observed did not reach statistical significance. Second, we contrasted studies that involved the use of a treatment manual (to standardize the interventions provided) with those that did not, and we also contrasted studies that involved some form of fidelity check (to verify that the interventions were conducted as intended) with those that did not. Neither of these two contrasts reached statistical significance (Table 2), indicating that studies were equally as effective with or without implementing these procedures.

Finally, we evaluated differences across four types of spiritual/religious interventions provided. As seen in Table 3, studies in which therapists explicitly taught clients spiritual concepts and related them to the clients’ situation/well-being were significantly more effective than studies that did not. Oppositely, studies in which clients were instructed in religious imagery or spiritual meditation were significantly less 
effective than studies that involved other types of interventions. Studies involving client prayer and reading sacred texts were equally as effective as those that did not involve these two interventions. We caution that these moderator analyses involved small numbers of research articles, such that the results may be influenced by random factors (e.g., sampling error) and other limitations discussed in the following section.

\section{Discussion}

The results of this meta-analytic review confirm that spiritual or religious adaptations to psychotherapy effectively benefit clients. The overall effect size across 31 studies of $d=.56$ is of moderately strong magnitude (Cohen, 1987) that is higher than the average value of $d=.48$ typically observed when psychotherapy outcomes are compared to those of control groups receiving a pseudo-intervention (i.e., Lambert \& Bergin, 1994). Furthermore, the average effect size across 16 experimental and 6 quasiexperimental studies that explicitly compared interventions with spiritual components to those that did not (e.g., religiously-oriented cognitive therapy vs. secular cognitive therapy) was of nearly equivalent magnitude $(d=.51)$ to that observed across all studies. Given that comparisons across different types of secular psychotherapy (e.g., cognitive vs. humanistic) typically result in effect size differences between $d=0$ to $d=.21$ (Wampold et al., 1997), spiritual psychotherapy approaches deserve ongoing investigation.

Notably, average client outcomes did not differ across their gender or age composition. This finding is important in verifying that spiritual approaches to psychotherapy may generalize across different populations. However, we observed that current outcome research in this area involves primarily Christian (73\%) and Muslim 
(24\%) clients. Therefore, we cannot currently ascertain the degree to which spiritual adaptations are effective for members of other religious faiths. Similarly, because most research currently involves Caucasian clients, we could not ascertain differences across client race. Future examinations should investigate diverse racial groups given notable differences in how religion is utilized and interpreted across cultures (e.g., Richards \& Bergin, 2000; Richards, Keller, \& Smith, 2004).

An interesting finding of this meta-analysis was that spiritual therapy approaches appeared to have a greater impact upon measures of well-being than upon other measures of mental health symptoms. This finding has several possible explanations that will need to be addressed in future research. It may be that spiritual interventions address quality of life issues (in a global sense) more than they address specific conditions associated with mental illness, such as panic attacks or sleep disturbance. It is also possible that overall client well-being might demonstrate more marked improvement than symptoms associated with psychological conditions, irrespective of the intervention provided. The finding may also be attributable to particular characteristics within and across the four particular studies that happened to measure well-being. The fact that these results involve only four studies greatly qualifies our ability to make inferences about the findings. Future outcome research that evaluates changes in both mental health symptoms and general well-being could shed additional light on the topic. Increased attention to outcome variables associated with positive psychological functioning appears warranted.

The quality of the results of any meta-analysis depends upon the characteristics of the studies included in the analysis. For example, this meta-analysis investigated studies 
using a wide variety of religious and spiritual interventions, so the summary data are not specific to a particular adaptation to psychotherapy. As more and more outcome studies are conducted, future meta-analyses will be able to more clearly ascertain trends within the data. In this particular meta-analysis, we were struck by several improvements in the quality of research compared with that observed by previous reviewers (McCullough, 1999; Worthington \& Sandage, 2001). Nevertheless, we also found methodological limitations across many of the research studies. First among these limitations was the moderate number of clients included in the research reports. The average number of clients was 60 and the highest number of clients was 189. Although this is a great improvement compared to the average of 22 clients found across the studies included in McCullough's (1999) meta-analysis, future research efforts should be given to increasing the number of clients evaluated because research findings with small numbers of clients can be greatly impacted by sampling error.

A second methodological issue involved client attrition. Eight manuscripts did not contain information regarding attrition, but several studies that did report this information experienced significant losses to the number of clients included in the analyses (Table 1). Although the attrition rates did not differ substantively across treatment vs. control groups, it is nevertheless possible that clients in the spiritual intervention groups may have discontinued due to factors related to the spiritual intervention (e.g., discomfort, values conflicts), such that the most spiritual or the most compliant clients remained in treatment. Analyses that control for initial client characteristics would be helpful in confirming that the positive effects of spiritual interventions are not attributable to those characteristics. 
Minor concerns could be raised with respect to procedures intended to ensure experimental internal validity and treatment fidelity. We were pleased to find that across 18 of the 31 studies clients were randomly assigned to treatment vs. control conditions, but the results of 6 quasi-experimental studies may have been biased due to possible differential selection to treatment condition. Sixteen of the studies used a treatment manual and 15 did not. Treatment manuals are not absolutely necessary in outcome research, but they do enhance the consistency with which interventions are implemented. Only seven of the studies performed a treatment fidelity check to ensure that the interventions were being implemented as intended. Three studies explicitly controlled for possible therapist effects, and five studies involved large enough numbers of therapists that the likelihood of differential outcomes being attributable to one particularly skilled clinician seemed negligible. Future outcome research in this area should explicitly address possible therapist allegiance effects as well as the influence of client expectations. Although these types of concerns apply to psychotherapy outcome research in general (Lambert \& Bergin, 1994), explicit attention to improve the rigor of experimentation should improve the interpretability of future data associated with spiritual approaches to psychotherapy.

Although this meta-analysis was restricted to empirical outcome research, we recognize the pressing need for psychotherapy process research regarding spiritual variables. We also hope that more single-subject, discovery-oriented, and qualitative studies in this domain will be conducted. And we hope that the number and quality of carefully designed experimental outcome studies on spiritual approaches will continue to increase. For example, dismantling studies may be useful in ascertaining particularly 
effective spiritual interventions, dose-effect studies may be necessary to determine the amount of spiritual intervention needed for substantive impact, and studies that explicitly address pre-existing client spiritual resources may be useful in determining how therapy may possibly augment clients’ current coping strategies. Increasingly, grant sponsors are needed to fund such large and complex initiatives. Although research funding for spiritual approaches has increased substantially during the past decade (Richards \& Bergin, 2005), we encourage increased funding in this area of inquiry given the data presented here.

\section{Conclusions}

Overall, the results of the present meta-analytic review indicate that spiritual approaches to psychotherapy are effective. Clinicians appear justified in using spiritual interventions, such as encouraging client prayer or reading sacred texts, following proper assessment of client spiritual beliefs and practices and client informed consent. The data also suggest that clients may particularly benefit when they learn to apply their own religious/spiritual beliefs to their mental health or well-being concerns. Interventions that facilitate client understanding and application of religious/spiritual teachings appear to be more effective than other types of interventions, but additional research will be needed to replicate this finding.

Despite the general empirical support uncovered in this literature review, there is still much that is not understood about spiritual approaches and interventions. For example, what types of methods work best with different types of clients? To what degree are spiritual approaches to psychotherapy effective because they enhance the quality of the relationship between the therapist and the religious client? Are spiritual 
approaches even more effective when clients explicitly request them? Can non-religious psychotherapists effectively provide spiritual approaches or accommodations requested by religious clients? How can spiritual fads, excesses, and commercializing be curbed while responsible experimentation continues? These and many other questions could be addressed through ongoing investigations. We hope that psychotherapy outcome and process researchers throughout the world will assist with this important task. 


\section{References}

References marked with an asterisk indicate studies included in the meta-analysis.

*Azhar, M. Z., \& Varma, S. L. (1995a). Religious psychotherapy as management of bereavement. Acta Psychiatrica Scandinavia, 91, 223-235.

*Azhar, M. Z., \& Varma, S. L. (1995b). Religious psychotherapy in depressive patients. Psychotherapy and Psychosomatics, 63, 165-173.

*Azhar, M. Z., Varma, S. L., \& Dharap, A. S. (1994). Religious psychotherapy in anxiety disorder patients. Acta Psychiatrica Scandinavia, 90, 1-3.

*Baker, D. C. (2000). The investigation of pastoral care interventions as a treatment for depression among continuing care retirement community residents. Journal of Religious Gerontology, 12(1), 63-85.

Ball, R. A., \& Goodyear, R. K. (1991). Self-reported professional practices of Christian psychologists. Journal of Psychology and Christianity, 10, 144-153.

Barnett, J. E., \& Fiorentino, N. (2000). Spirituality and religion: Clinical and ethical issues for psychotherapists. Part II. Psychological Bulletin, 35, 32-35.

Begg, C. B. (1994). Publication bias. In H. Cooper and L. V. Hedges (Eds.) The handbook of research synthesis (pp. 399-409). New York: Russell Sage Foundation.

Butler, M. H. \& Harper, J. M. (1994). The Divine Triangle: God in the marital system of religious couples. Family process, 33, 277-286.

*Chan, C. L., Chan, Y., \& Lou, V. W. (2002). Evaluating an empowerment group for divorced Chinese women in Hong Kong. Research on Social Work Practice, 12, 558-569. 
Chappelle, W. (2000). A series of progressive legal and ethical decision-making steps for using Christian spiritual interventions in psychotherapy. Journal of Psychology and Theology, 28, 43-53.

Cohen, J. (1987). Statistical power analysis for the behavioral sciences. Hillsdale, NJ: Erlbaum.

*Cole, B. S. (2005). Spiritually-focused psychotherapy for people diagnosed with cancer: A pilot outcome study. Mental Health, Religion and Culture. 8, 217-226.

*Craigie, F. C. (1992). Evaluation and six-year follow-up of a community-based Christian cognitive-behavioral stress management program. Journal of Psychology and Christianity, 11, 269-276.

*Davis, T. L., \& C. E. Hill (2005). Spiritual and nonspiritual approaches to dream work: effects on clients’ well-being. Journal of Counseling and Development, 83, 492503.

Duval, S., \& Tweedie, R. (2000a). A non-parametric “trim and fill” method of accounting for publication bias in meta-analysis. Journal of the American Statistical Association, 95, 89-98.

Duval, S., \& Tweedie, R. (2000b). Trim and fill: A simple funnel-plot based method of testing and adjusting for publication bias in meta-analysis. Biometrics, 56, 455463.

Elkins, D. N. (1995). Psychotherapy and spirituality: Toward a theory of the soul. Journal of Humanistic Psychology, 35(2), 78-98.

*Emery, E. E. (2002). Living history—spiritually. . or not? A comparison of conventional and spiritually-integrated reminiscence groups. Unpublished 
doctoral dissertation, Bowling Green State University, OH.

Epstein, M. (1995). Thoughts without a thinker: Psychotherapy from a Buddhist perspective. New York: Basic Books.

Faiver, C., Ingersoll, R. E., O’Brien, E. M., \& McNally, C. (2001). Explorations in counseling and spirituality: Philosophical, practical, and personal reflections. Belmont, CA: Thomson/Learning-Brooks/Cole.

*Finney, J. R. \& Malony, H. N. (1985). An empirical study of contemplative prayer as an adjunct to psychotherapy. Journal of Psychology and Theology, 13, 284-290.

Fowler, J. (1991). Stages in faith consciousness. In F. K. Oser \& W. G. Scarlett (Eds.), Religious development in childhood and adolescence [Special issue]. New Directions for Child Development, 52, 27-45.

Griffith, J. L., \& Griffith, M. E. (2002). Encountering the sacred in psychotherapy: How to talk with people about their spiritual lives. New York: Guilford.

*Guinn, B. \& Vincent, V. (2002). A health intervention on Latina spiritual well-being constructs: an evaluation. Hispanic Journal of Behavioral Sciences, 24 (3), 379391.

Harris, E. S. (2000). God, buber and the practice of Gestalt therapy. Gestalt Journal, 23(1), 39-62.

Haug, I. E. (1998). Including a spiritual dimension in family therapy: Ethical considerations. Contemporary Family Therapy, 20, 181-194.

Hawkins, I. L., \& Bullock, S. L. (1995). Informed consent and religious values: A neglected area of diversity. Psychotherapy, 32, 293-300.

*Hawkins, R. S., Tan, S. Y. \& Turk, A. A. (1999). Secular versus Christian inpatient 
cognitive-behavioral therapy programs: impact on depression and spiritual wellbeing. Journal of Psychology and Theology, 27, 309-318.

Hedayat-Diba, Z. (2000). Psychotherapy with Muslims (pp. 289-314), In P. S. Richards, \& A. E. Bergin (Eds.). (2000). Handbook of psychotherapy and religious diversity. Washington, DC: American Psychological Association.

Hedges, L. V., \& Vevea, J. L. (1998). Fixed- and random-effects models in metaanalysis. Psychological Methods, 3, 486-504.

Helminiak, D. A. (1996). The human core of spirituality: Mind as psyche and spirit. Albany, NY: State University of New York Press.

Hiatt, J. F. (1999). A transpersonal care program in an institutional setting. Psychiatricannals, 29(8), 480-483.

Hood, R. W., Jr., Spilka, B., Hunsberger, B., \& Gorsuch, R. (1996). The psychology of religion: An empirical approach ( $2^{\text {nd }}$ ed.). New York: Guilford Press.

*Jackson, R. E. (1999). Reducing shame through forgiveness and empathy: a group therapy approach to promoting prosocial behavior. Unpublished doctoral dissertation, Fuller Theological Seminary, Pasadena, CA.

Johnson, B. W. (1993). Outcome research and religious psychotherapies: Where are we and where are we going? Journal of Psychology \& Theology, 21, 297-308.

*Johnson, B. W. \& Ridley, C. R. (1992). Brief Christian and non-Christian rationalemotive therapy with depressed Christian clients: An exploratory study. Counseling and Values, 36, 220-229.

*Johnson, B. W., Devries, R., Ridley, C. R., Pettorini, D., Peterson, D. R. (1994). The comparative efficacy of Christian and secular rational-emotive therapy with 
Christian clients. Journal of Psychology and Theology, 22, 130-140.

Kelly, E. W. (1995). Religion and spirituality in counseling and psychotherapy. Alexandria, VA: American Counseling Association.

Koenig, H. G. (Ed.) (1998). Handbook of religion and mental health. San Diego, CA: Academic.

Lambert, M. J. \& Bergin, A. E. (1994). The effectiveness of psychotherapy. In A. E. Bergin \& S. L. Garfield (Eds.) Handbook of psychotherapy and behavior change (4th ed., pp. 143-189). New York: Wiley.

Lannert, J. L. (1991). Resistance and countertransference issues with spiritual and religious clients. Journal of Humanistic Psychology, 31, 68-76.

*Layer, S. D., Roberts, C., Wild, K., \& Walters, J. (2004). Postabortion grief: Evaluating the possible efficacy of a spiritual group intervention. Research on Social Work Practice, 14, 344-350.

Lipsey, M. W., \& Wilson. D. B. (2001). Practical meta-analysis. Thousand Oaks, CA: Sage.

Lovinger, R. J. (1984). Working with religious issues in therapy. Northwale, NJ: Jason Aronson.

Lyons, L. (1996). The meta-analysis calculator [Computer software]. Manassas, VA: Author.

Maher, A. R. (1996). Existential-humanistic psychotherapy and the religious person. In E. P. Shafranske (Ed), Religion and the clinical practice of psychology (pp. 433460). Washington, DC: American Psychological Association.

Martin, J. E. \& Booth, J. (1999) Behavioral approaches to enhance spirituality. In W. R. 
Miller (Ed.), Integrating spirituality into treatment: Resources for practitioners (pp.161-175). Washington, DC: American Psychological Association.

McCullough, M. E. (1999). Research on religion-accommodative counseling: Review and meta-analysis. Journal of Counseling Psychology, 46, 92-98.

*McGee, M. A. (1998). Spiritual heath and its relation to levels of perceived stress among a sample of university students. Unpublished doctoral dissertation, University of New Mexico, Albuquerque.

McMinn, M. R. (1996). Psychology, theology, and spirituality in Christian counseling. Wheaton, Illinois: Tyndale House Publishers.

*Meany, J., McNamara, M, \& Burks, V. (1984). The effectiveness of the "Jesus Prayer" and relaxation on stress reduction as measured by thermal biofeedback. The Journal of Pastoral Counseling, 19, 63-67.

Miller, W. R. (1999). Integrating spirituality into treatment: Resources for practitioners. Washington, DC: American Psychological Association. Miller, L. (2004). A spiritual formulation of interpersonal psychotherapy for depression in pregnant girls. In P. S. Richards \& A. E. Bergin (Eds.). Casebook for a spiritual strategy in counseling and psychotherapy (pp. 75-86). Washington, D.C.: American Psychological Association.

Mosteller, F., \& Colditz, G. A. (1996). Understanding research synthesis (meta-analysis). Annual Review of Public Health, 17, 1-23.

Nielsen, S. L., Johnson, W. B., \& Ellis, A. (2001). Counseling and psychotherapy with religious persons: A rational emotive behavior therapy approach. Mahwah, New Jersey: Lawrence Erlbaum. 
*Nohr, R. W. (2001). Outcome effects of receiving a spiritually informed vs. a standard cognitive-behavioral stress management workshop. Dissertation Abstracts International-Section B-The Sciences and Engineering. 61 (7-B), 3855.

*O’Hare, C. (2002). Challenging God images: Implementing a Christian component within a standard group therapy intervention. Unpublished doctoral dissertation, Regent University, Virginia Beach, VA.

*Pecheur, D. R. \& Edwards, K. J. (1984). A comparison of secular and religious versions of cognitive therapy with depressed Christian college students. Journal of Psychology and Theology, 12, 45-54.

Propst, L. R. (1996). Cognitive-behavioral therapy and the religious person. In E. P. Shafranske (Ed.), Religion and the clinical practice of psychology (pp. 391-407). Washington, DC: American Psychological Association.

*Propst, L. R., Ostrom, R., Watkins, P., Dean, T. \& Mashburn, D. (1992). Comparative efficacy of religious and nonreligious cognitive-behavioral therapy for the treatment of clinical depression in religious individuals. Journal of Consulting and Clinical Psychology, 60, 94-103.

Rabinowitz, A. (1999). Judaism and psychology: Meeting points. New Jersey: Jason Aronson.

Rabinowitz, A. (2000). Psychotherapy with orthodox Jews. In P. S. Richards \& A. E. Bergin (Eds.), Handbook of psychotherapy and religious diversity (pp. 237-258). Washington, DC: American Psychological Association.

Raphel, M. M. (2001). The status of the use of spiritual interventions in three professional mental health groups. (Doctoral dissertation, Loyola College, 2001). 
Dissertation Abstracts International, Section A: Humanities \& Social Sciences, 62 (2-A), 779.

*Razali, S. M., Aminah, K. \& Khan, A. U. (2002). Religious-cultural psychotherapy in the management of anxiety in patients. Transcultural Psychiatry, 39, 130-136.

*Razali, S. M., Hasanah, C. I., Aminah, K. \& Subramaniam, M. (2001). Religioussociocultural psychotherapy in patients with anxiety and depression. Australian and New Zealand Journal of Psychiatry, 32, 867-872.

Richards, P. S., \& Bergin, A. E. (1997). A spiritual strategy for counseling and psychotherapy. Washington, DC: American Psychological Association.

Richards, P. S., \& Bergin, A. E. (2005). A spiritual strategy for counseling and psychotherapy ( $2^{\text {nd }}$ ed.). Washington, DC: American Psychological Association.

Richards, P. S., \& Bergin, A. E. (Eds.). (2000). Handbook of psychotherapy and religious diversity. Washington, D.C.: American Psychological Association.

*Richards, P. S., Berrett, M. E., Hardman, R. K., \& Eggett, D. L. (2006). Comparative efficacy of spirituality and cognitive groups for treating eating disorder inpatients. Eating Disorders: Journal of Treatment and Prevention, 14, 401-415.

Richards, P. S., Keller, R., Smith, T. B. (2004). Religious and spiritual diversity in the practice of psychotherapy (pp. 269-286). In T. B. Smith (Ed.) Practicing multiculturalism: Affirming diversity in counseling and psychology. Boston: Allyn \& Bacon.

*Richards, P. S., Owen, L., Stein, S. (1993). A religiously oriented group counseling intervention for self-defeating perfectionism: a pilot study. Counseling and Values, 37, 96-105. 
Richards, P. S., \& Potts, R. W. (1995). Using spiritual interventions in psychotherapy: Practices, successes, failures, and ethical concerns of Mormon psychotherapists. Professional Psychology: Research and Practice, 26, 163-170.

Rosenthal, R. (1979). The “file drawer problem” and tolerance for null results. Psychological Bulletin, 86, 638-641.

Rubin, J. B. (1996). Psychotherapy and Buddhism: Toward an integration. New York: Plenum Press.

*Rye, M. S., \& Pargament, K. I. (2002). Forgiveness and romantic relationships in college: Can it heal the wounded heart? Journal of Clinical Psychology, 58, 419441.

*Rye, M. S., Pargament, K. I, Pan, W., Yingling, D. W., Shogren, K. A., Ito, M. (2005). Can group interventions facilitate forgiveness of an ex-spouse? A randomized clinical trial. Journal of Consulting and Clinical Psychology, 73, 880-892.

Shafranske, E. P. (2000). Religious involvement and professional practices of psychiatrists and other mental health professionals. Psychiatric Annals, 30, 525532.

Shafranske, E. P. (2001). The religious dimension of patient care within rehabilitation medicine: The role of religious attitudes, beliefs, and professional practices. In T. G. Plante \& A. C. Sherman, (Eds.). Faith and health: Psychological perspectives (pp. 311-335). New York: The Guilford Press.

Shafranske, E. P. (2004). A psychodynamic case study. In P. S. Richards (Ed), Casebook for a spiritual strategy in counseling and psychotherapy (pp. 153-170). Washington, DC: American Psychological Association. 
Shrout, P. E., \& Fleiss, J. L. (1979). Intraclass correlations: Uses in assigning rater reliability. Psychological Bulletin, 86, 420-428.

Smith, T. B., \& Richards, P. S. (2005). The integration of spiritual and religious issues in racial-cultural psychology and counseling. In R. T. Carter (Ed.): Handbook of racial-cultural psychology and counseling: Theory and research (vol. 1). Pp. 132160. New York: Wiley.

Sonne, J. L. (1999). Multiple relationships: Does the new ethics code answer the right questions. In D. N. Bersoff (Ed.), Ethical conflicts in psychology ( $2^{\text {nd }}$ ed., pp. 227230). Washington, DC: American Psychological Association.

Sperry, L. \& Shafranske, E. P. (Eds.) (2005). Spiritually-oriented psychotherapies. Washington, DC: American Psychological Association.

Steinfield, G. J. (2000). Spiritual psychology and psychotherapy: Is there theoretical and empirical support? Journal of contemporary psychotherapy, 30(4), 353-380.

*Tarakeshwar, N., Pearce, M. J. \& Sikkema, J. (2005). Development and implementation of a spiritual coping group intervention for adults living with HIV/AIDS: A pilot study. Mental Health, Religion \& Culture, 8, 179-190.

*Targ, E. F. \& Levine, E. G. (2002). The efficacy of a mind body spirit group for women with breast cancer: a randomized trial. General Hospital Psychiatry, 24, 238-248.

Trautmann, R. L. (2003). Psychotherapy and spirituality. Transactional analysis Journal, 33(1), 32-36.

Wampold, B. E., Mondin, G. W., Moody, M., Stich, F., Benson, K., \& Ahn, H. (1997). A meta-analysis of outcome studies comparing bona fide psychotherapies: “All must have prizes.” Psychological Bulletin, 122, 203-215. 
Watts, R. E., (2000). Biblically based Christian spirituality and Adlerian psychotherapy. Journal of individual psychology, 56 (3), 316-328.

West, W. (2000). Psychotherapy and spirituality: Crossing the line between therapy and religion. Thousand Oaks: Sage.

West, W. (2004). Humanistic integrative spiritual psychotherapy. In P. S. Richards (Ed.), Casebook for a spiritual strategy in counseling and psychotherapy (pp. 201-230). Washington, DC: American Psychological Association.

Worthington, E. L., Jr., Kurusu, T. A., McCollough, M. E., \& Sandage, S. J. (1996). Empirical research on religion and psychotherapeutic processes and outcomes: A ten-year review and research prospectus. Psychological Bulletin, 119, 448-487.

Worthington, E. L., Jr., \& Sandage, S. J. (2001). Religion and spirituality. Psychotherapy, 38, 473-478.

*Zimmerman, G. L. \& Meier, A. (1999). Outcomes in pastoral counseling: effects of focusing and Christian contemplative meditation on trust correlates. American Journal of Pastoral Counseling, 2(2), 67-88. 
Table 1

Description, Findings and Characteristics of Spiritually-Oriented Treatment Outcome Studies

\begin{tabular}{|c|c|c|c|c|c|c|}
\hline Author, Year & $\mathrm{N}$ & Attrition & Population & Clinical Issues & Spiritual Treatment & Outcome \\
\hline Azhar, Varma \& & 62 & $19 \%$ & Devout Malaysian Muslims & Anxiety Disorder & Discussion of religious issues & At 3 months of treatment religious \\
\hline \multirow[t]{2}{*}{ Dharap (1994) } & & & & & specific to patients, Koran readings & group was significantly better, but \\
\hline & & & & & and prayer & not at 6 months \\
\hline Azhar \& Varma & 30 & NR & Muslim Bereavement & Anxiety Disorder & Discussion of religious issues in a & Religious treatment group \\
\hline (1995) & & & Patients & & CBT fashion, scripture and prayer & significantly more effective \\
\hline Azhar \& Varma & 64 & $6 \%$ & Devout Malaysian Muslims & Depression & Discussion of religious issues, & Religious treatment group more \\
\hline \multirow[t]{2}{*}{ (1995) } & & & & & Koran reading, prayer encouraged & effective at 1 and 3 months but not \\
\hline & & & & & and lifestyle advice & at 6 months \\
\hline \multirow[t]{2}{*}{ Baker (2000) } & 120 & NR & Retirement Community & Depression & Prayer, counseling, grief work, & Treatment group improved more \\
\hline & & & Residents & & listening, life review and blessings. & but not statistically significantly \\
\hline Chan, Chan, \& & 67 & NR & Divorced Chinese Women & Empowerment and & Integrated Eastern religious & Significant changes were made in \\
\hline Lou (2002) & & & & Stress reduction & content, acupressure, body work on & their perceived levels of stress and \\
\hline & & & & & meridian, forgiveness, etc. & sense of empowerment \\
\hline
\end{tabular}


Table 1 (continued). $\quad$ Description, Findings and Characteristics of Spiritually-Oriented Treatment Outcome Studies

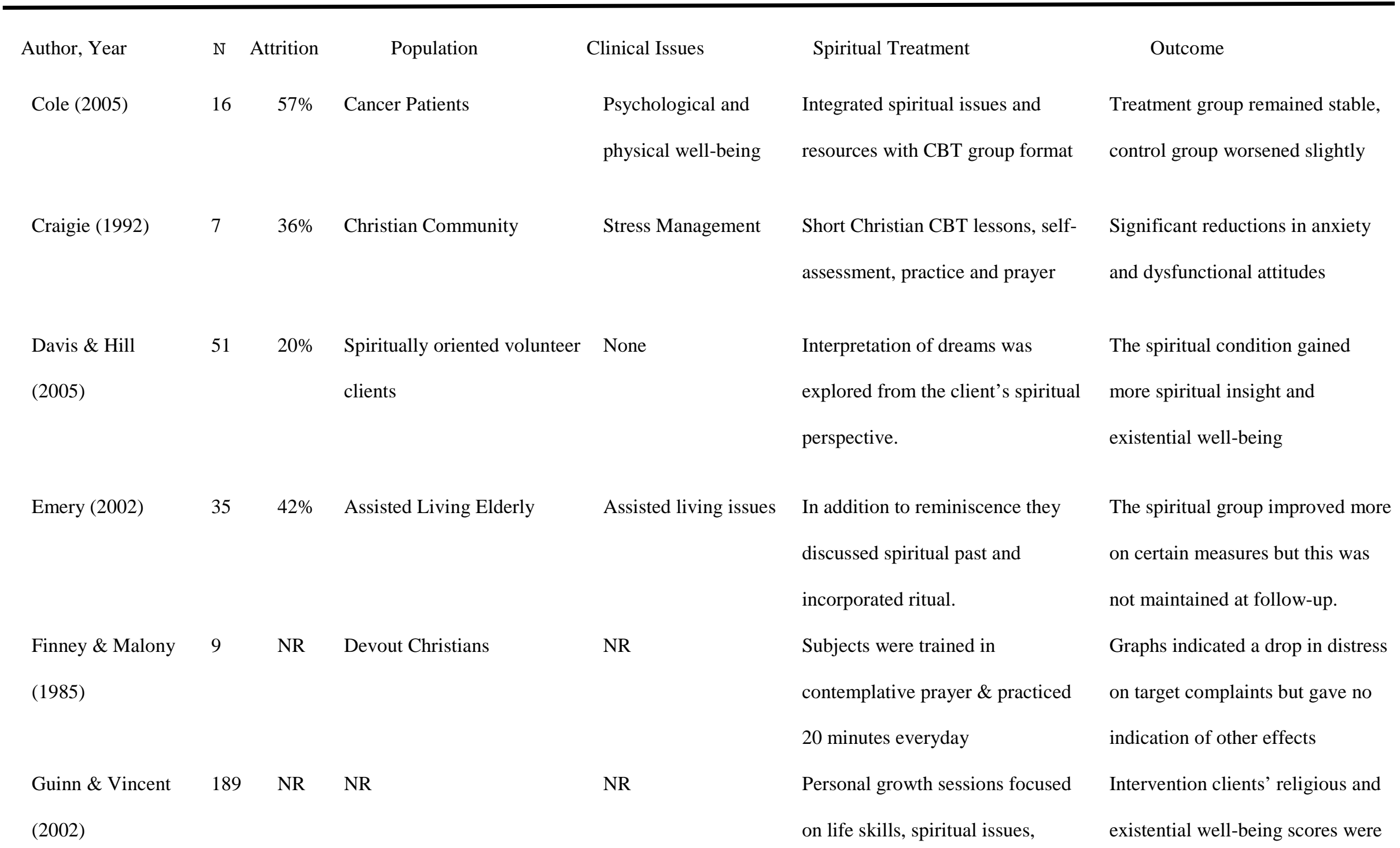


Spiritual Approaches 34

personat retationstinps, Bible study, significantly highter than controt

values, etc

clients 


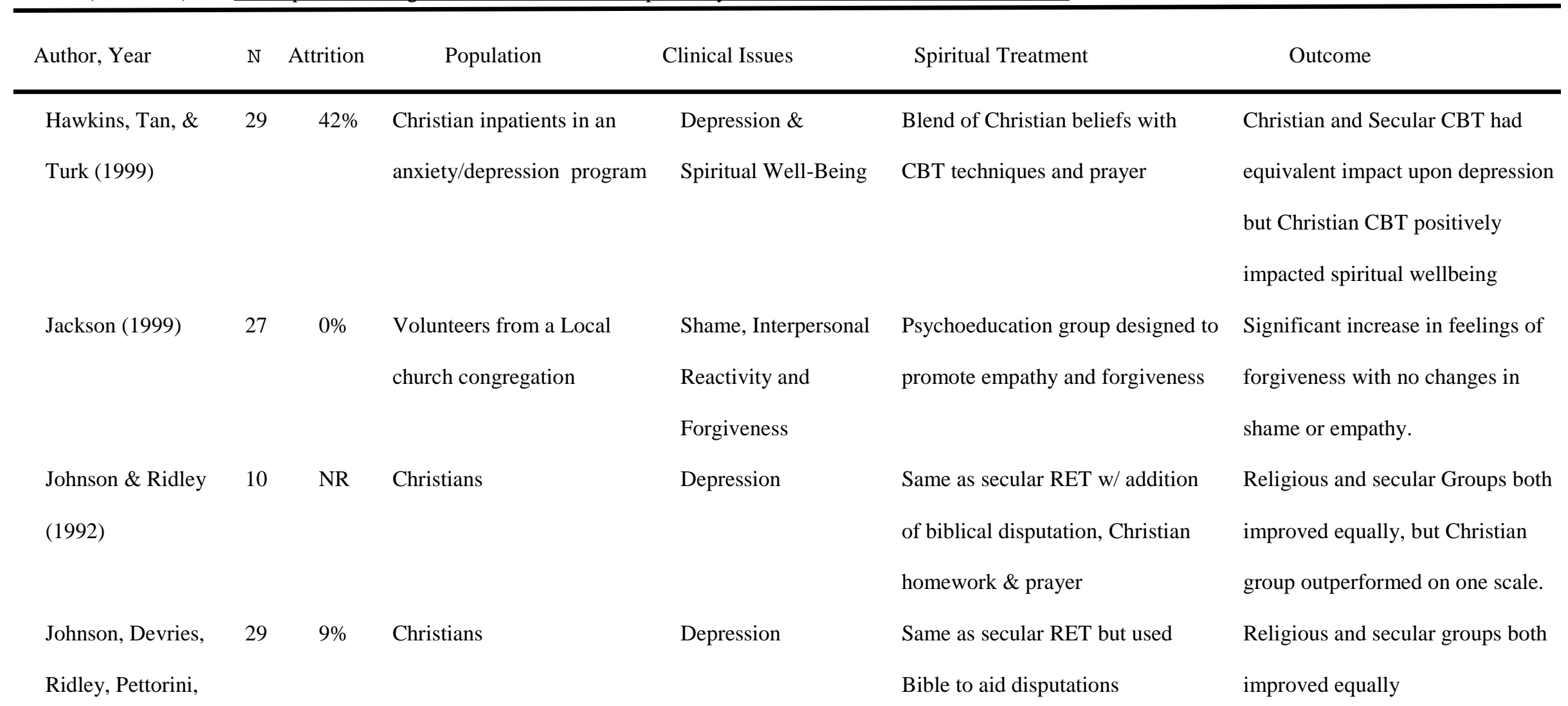

\& Peterson (1994) 


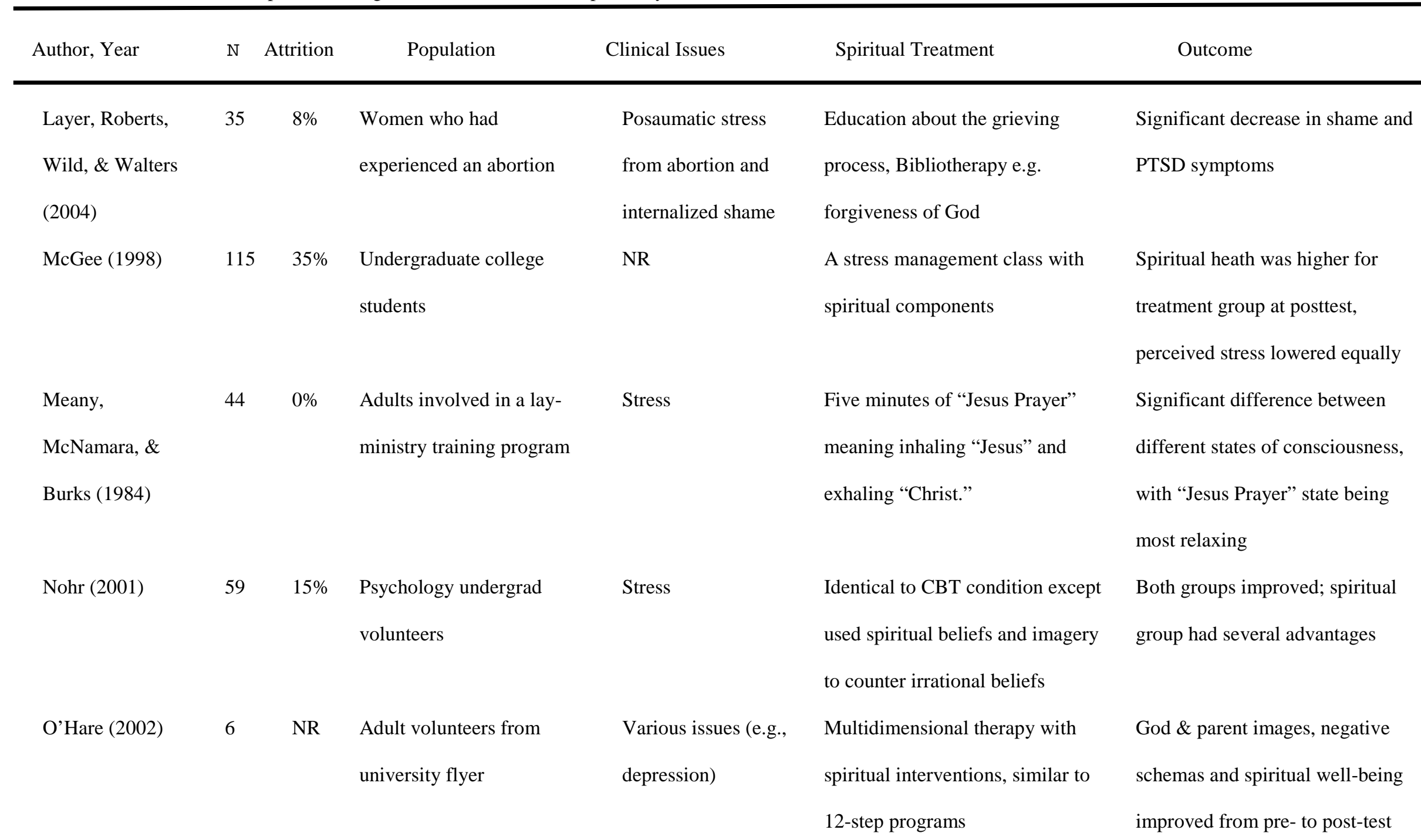




\begin{tabular}{|c|c|c|c|c|c|c|}
\hline Author, Year & $\mathrm{N}$ & Attrition & Population & Clinical Issues & Spiritual Treatment & Outcome \\
\hline Pecheur \& & 21 & $0 \%$ & Christian College students & Depression & CBT for depression with biblical & Secular and religious CBT groups \\
\hline \multirow[t]{2}{*}{ Edwards (1984) } & & & & & teachings regarding the self, the & were equally more effective than a \\
\hline & & & & & world and the future & control group \\
\hline Propst, Ostrom, & 59 & $11 \%$ & General Christian & Depression & Religious rationales, arguments & Religious groups had reductions \\
\hline Watkins, Dean, \& & & & Community & & and imagery to counter irrational & of depression and improvement in \\
\hline \multirow[t]{2}{*}{ Mashburn (1992) } & & & & & beliefs & social adjustment; groups were \\
\hline & & & & & & equal at follow-up \\
\hline Razali, Aminah \& & 165 & $18 \%$ & Malays with depressive and & Anxiety and & Standard treatment plus religious & Religious group responded faster \\
\hline \multirow[t]{3}{*}{ Khan (2002) } & & & anxiety disorders attending & Depression & component e.g. encouragement to & than those in standard group, but \\
\hline & & & a hospital psychiatric clinic & & pray, read the Koran, change & difference became non-significant \\
\hline & & & & & lifestyles, etc. & at the end of six months \\
\hline Razali, Hasanah, & 203 & $15 \%$ & Malay patients of a & Anxiety & Standard treatment plus religious- & Religious group showed more \\
\hline Aminah \& & & & university psychiatric clinic & & cultural therapy involving & rapid improvement; however, no \\
\hline Subramaniam & & & diagnosed with Generalize & & modification of cognitions guided & difference was seen between \\
\hline (2001) & & & Anxiety Disorder. & & by the Koran and Hadith & groups at the end of six months. \\
\hline
\end{tabular}




\begin{tabular}{|c|c|c|c|c|c|c|}
\hline Author, Year & $\mathrm{N}$ & Attrition & Population & Clinical Issues & Spiritual Treatment & Outcome \\
\hline Richards, Berret, & 122 & $0 \%$ & Inpatient eating disordered & Eating Disorders & Read spirituality workbook and & Spiritual group somewhat better \\
\hline Hardman \& & & & women & & processed readings in weekly & than secular groups for \\
\hline \multirow[t]{2}{*}{ Eggett (2006) } & & & & & group & psychological disturbance \& \\
\hline & & & & & & spiritual wellbeing \\
\hline Richards, Owen \& & 15 & $29 \%$ & Mormon college students & Perfectionism & Religiously oriented cognitive & Clients improved significantly \\
\hline Stein (1993) & & & who volunteered & & group therapy & \\
\hline Rye \& Pargament & 58 & NR & Christian College Women & Forgiveness, & Same as secular group with the & Religious and Secular groups both \\
\hline$(2002)$ & & & & existential well-being & addition of spiritual components & improved equally \\
\hline \multirow[t]{4}{*}{ Rye et al. (2005) } & 149 & $18 \%$ & Divorced individuals & Forgiveness and & Structured psycho-educative & Intervention groups increased in \\
\hline & & & & mental health & sessions plus encouragement to & forgiveness more than the control \\
\hline & & & & & draw on religious sources of & group. The secular group \\
\hline & & & & & support when forgiving & decreased most in depression. \\
\hline Tarakeshwar, & 13 & $7 \%$ & HIV / AIDS patients & Mental health and & Cognitive therapy within a spiritual & Higher self-rated religiosity, more \\
\hline Pearce \& Sikkema & & & & spiritual coping & coping framework & use of positive spiritual coping, \\
\hline$(2005)$ & & & & & & and lower depression. \\
\hline
\end{tabular}


Table 1 (continued). $\quad$ Description, Findings and Characteristics of Spiritually-Oriented Treatment Outcome Studies

\begin{tabular}{|c|c|c|c|c|c|c|}
\hline Targ, \& Levine & 132 & $20 \%$ & Breast Cancer Patients & Quality of life, & Intensive lifestyle change and & Spiritual and secular groups \\
\hline \multirow[t]{2}{*}{$(2002)$} & & & & Depression, Anxiety, & group support program with & improved equally on most \\
\hline & & & & Spiritual Well-being, & emphasis on psychospiritual & psychological measures. \\
\hline Zimmerman,\& & 24 & $0 \%$ & Volunteers & Trust, mood, self- & Encourages quiet listing to God & Both groups improved but the \\
\hline \multirow[t]{3}{*}{ Meier (1999) } & & & & esteem, faith & and letting go of control and & Christian meditation group had \\
\hline & & & & maturity, and client & risking openness to new & more robust, longer lasting effe \\
\hline & & & & satisfaction & experiences. & \\
\hline
\end{tabular}

$\mathrm{NR}=$ Not reported in the article 
Table 2

Random Effects Weighted Mean Effect Sizes (d) Across Study Characteristics.

Variable $\quad Q_{\mathrm{b}} \quad$ p $\quad \mathrm{k} \quad d \quad$

Population Evaluated

Normal community members

Religious institution affiliation

Mental health clients

Medical treatment patients

Multiple sites (more than one of the above)

Research Design

Experimental

Single Group Pre- to Post-test

Outcome Measurement Type

Wellbeing

Mental Health Symptoms

Multidimensional Assessments

Treatment Modality

Individual Therapy

Group Therapy
$4.1 \quad .39$

$6 \quad .53$

$9 \quad .49$

$6 \quad .75$

$5 \quad .29$

$5 \quad .66$

$1.9 \quad .17$

$24 \quad .51$

$\begin{array}{ll}7 & .78\end{array}$

$5.1 \quad .08$

$4 \quad .96$

$8 \quad .58$

$19 \quad .46$

$.8 \quad .36$

$8 \quad .42$

$22 \quad .58$ 
Table 2 (cont.)

\begin{tabular}{lcccc}
\hline \multicolumn{1}{c}{ Variable } & $Q_{\mathrm{b}}$ & $p$ & $\mathrm{k}$ & $d$ \\
\hline Treatment Manual & & & & \\
Yes & .1 & .72 & & \\
No & & & 16 & .54 \\
Treatment Fidelity Check & & & 15 & .59 \\
Yes & .3 & .59 & & \\
No & & & 9 & .59 \\
& & & & \\
\end{tabular}

Note. $\mathrm{Q}_{\mathrm{b}}=\mathrm{Q}$-value for variance between groups. This statistic is comparable to the Fvalue in ANOVAs. $\mathrm{K}=$ number of studies. $d=$ standardized mean difference, the effect size used in this meta-analysis. 
Table 3

Random Effects Weighted Mean Effect Sizes (d) Across Types of Spiritual Adaptations Made to Psychotherapy.

\begin{tabular}{|c|c|c|c|c|}
\hline Variable & $Q_{\mathrm{b}}$ & $p$ & $\mathrm{k}$ & $d$ \\
\hline Teaching Spiritual Concepts & 3.2 & .07 & & \\
\hline Yes & & & 14 & .69 \\
\hline No & & & 17 & .44 \\
\hline Religious Imagery/Meditation & .45 & .03 & & \\
\hline Yes & & & 10 & .32 \\
\hline No & & & 21 & .65 \\
\hline Client Prayer & .1 & .72 & & \\
\hline Yes & & & 13 & .59 \\
\hline No & & & 18 & .54 \\
\hline Religious Bibliotherapy & .2 & .68 & & \\
\hline Yes & & & 9 & .61 \\
\hline No & & & 22 & .54 \\
\hline
\end{tabular}

Note. $\mathrm{Q}_{\mathrm{b}}=\mathrm{Q}$-value for variance between groups. This statistic is comparable to the Fvalue in ANOVAs. $\mathrm{K}=$ number of studies. $d=$ standardized mean difference, the effect size used in this meta-analysis. 


\section{Figure Caption}

Figure 1. Plot of effect sizes (d) as a function of sample size. 
Spiritual Approaches 44

Figure 1

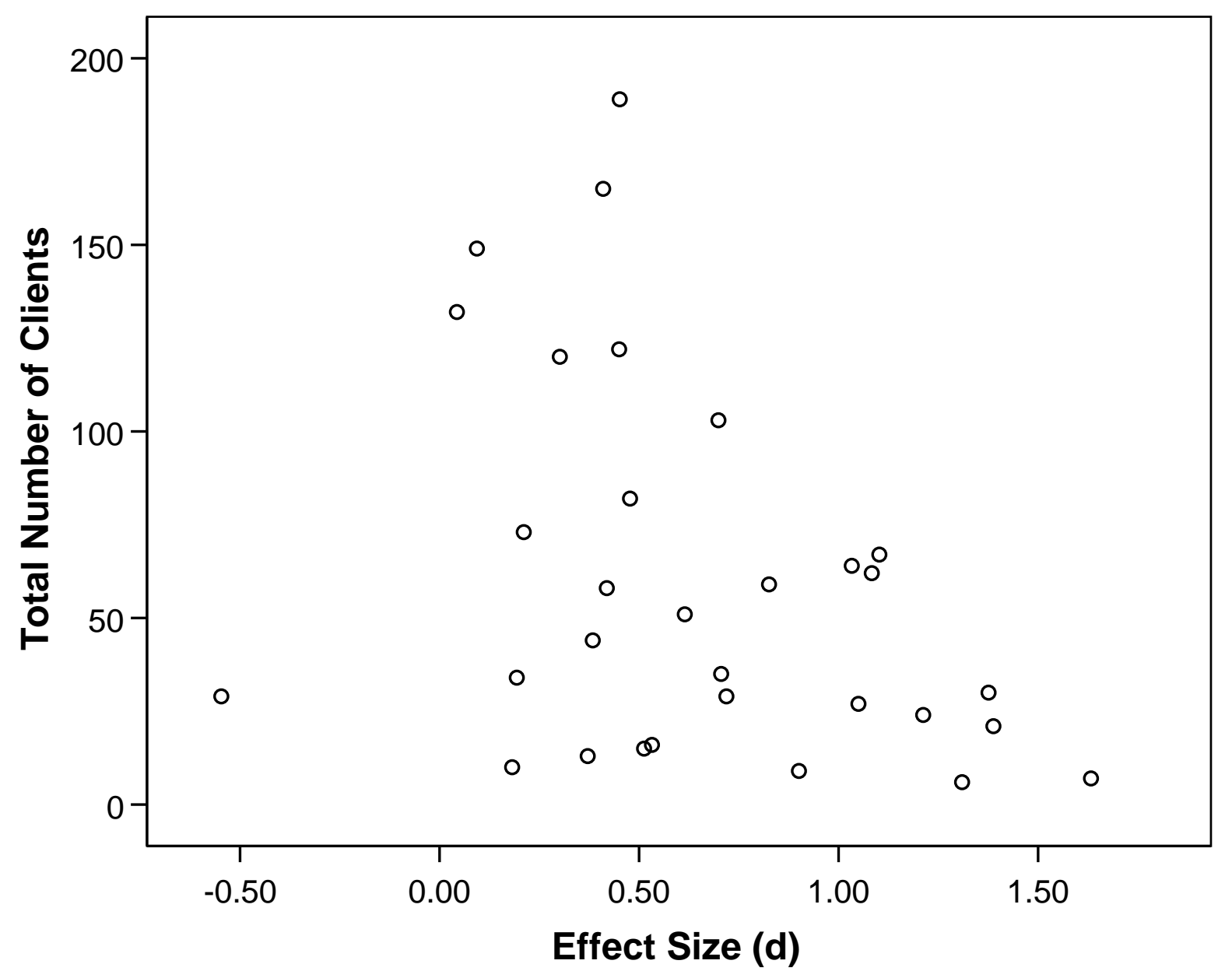

